\title{
Reflection in Teaching
}

\section{Ghassoub Mustafa}

\author{
Dubai Women's College
}

Learning and Teaching in Higher Education: Gulf Perspectives

Vol 2 No 2, June 2005

\begin{abstract}
The first part presents a review of concepts relating to reflection, drawing on the literature in this area. This literature review relates to the following aspects of reflection: the definition of reflection, the process of reflection, strategies in reflection, content of reflection, barriers to reflection, and advantages of reflection.

The second part of this paper presents an investigation into the perceptions of a small sample of English language educators and supervisors, through personal interviews with 9 teachers and 3 supervisors from one higher education institution and other educational institutions in the United Arab Emirates. The findings of the investigation are analyzed with respect to the dimensions that appear in the literature review. These findings show that the teachers do have some knowledge of reflection. They reveal that the teachers: attitudes towards reflection and its applicability in the teaching and learning process is largely positive, mixed with some degree of skepticism. Teachers agree that reflection is useful, but many seem uncertain about how it can be applied in their situation. In some cases the interviewees seemed to be more concerned about the technicalities of their job, making collaborative reflection appear less of a priority.
\end{abstract}

\section{Introduction}

In the recent literature on teacher education and in higher education in general, considerable attention has been devoted to reflection, or reflectivity as some call it: "reflection has come widely to be recognised as a crucial element in the professional growth of teachers: (Calderhead and Gates, 1993:1). For that reason, Copeland et al (1993:357) affirm that "Teacher educators appear to be eager to promote reflectivity among their students. There currently exists a number of growing teacher education programmes that are explicitly dedicated to reflectivity as an educational goal". They also comment on this trend, saying "Reflection has become one of the most popular issues in teacher education. The literature is replete with accounts of the reported success of reflective practitioners in changing and improving their own teaching" (ibid:374).

The educator has often been viewed as a technician, a disseminator of curriculum and knowledge. But increasingly we are concerned with exploring the thoughtful, insightful, and professional capabilities of the educator. "With education in some countries becoming highly politicized, reflective teaching has also been associated with a call for teacher empowerment, emancipation, enabling educators to examine ideologies critically and to consider the value basis of their own practice" (Calderhead and Gates, 1993:2). So, reflectivity is in demand in many countries as their education systems are becoming more sophisticated; for that reason, there has been a growing pressure on educators to reconsider their attitudes, approaches and personal beliefs. It is seen by many that reflectivity will be one of the tools that assist educators in re-evaluating their practices in teaching, which is expected to lead to a great improvement in the education profession.

\section{Definition of Reflection}

The term :reflection: has been conceptualised in numerous ways by people and professionals in the teaching field. LaBosky (1993) claims that in her study of the definitions of reflection, she has found the definitions to be inconsistent. Furthermore, there is no single definition that seems to embody all the aspects of reflective teaching programs. Williams (1999) adds that there has been a proliferation of terms that relate to reflection. and Bengtsson (1995:24-5) attempts to review the different facets of the concept:

\footnotetext{
"The term reflection hides a variety of different ideas on the nature of reflection and its implication for the teaching profession and teacher education. This situation is partly mirrored in the jungle of expressions that circulate:some of the recurring expressions are 'reflecting teaching', reflective practice, the teacher as researcher, the teacher as decision-maker, reflective thinking, the teacher as problem-solver, inquiry-oriented education, reflection-in-action, and the teacher as professional."
}

Bengtsson discusses the physical aspect that the word reflection denotes. Bengtsson explains that when a person looks at him/herself in the mirror, he/she can discover him/herself as a physical existence. However, metaphorically, when a person reflects, he/she reveals the reality inside him/herself and exposes it for scrutiny. :In the human context:[by] reflection is sometimes meant meditation, thinking, cognition and similar intellectual activities" (p.27). As a result of this 
meditation, a certain reality is focused on and is dealt with. Bengtsson explains: "In this sense, reflection means that some phenomenon is subjected to thorough consideration, that thought dwells a longer period of time on an object in order to get better and deeper understanding of it" (ibid:26).

Others have conceptualized the reflective educator as the reflective practitioner, i.e. 'teacher as researcher', or 'teacher as inquirer'. In the case of student teachers, the purpose behind this is to encourage them to link theory with practice by involving them in research and providing them with real life experience (Reis Jorge,1997). To this meaning, Lucas (1991) adds that reflection is a systematic inquiry into one's own practice to deepen one's own understanding of it. Russell and Munby (1992:8) affirm this definition of the term reflection as they :find the term productive: it encourages us to think about our work and search for productive frames.: Furthermore reflectivity, according to the literature, is not confined to one:s own work only; reflecting on others: work is also necessary.

Reflective thinking may generate reflective action, and in this sense Baird (1992:40) provides a more comprehensive definition of reflection that outlines a certain process with desirable outcomes: "a conscious, thoughtful, purpose-related process. Reflective processes such as asking evaluative questions, selecting procedures to answer these questions, evaluating the results and making appropriate decisions may lead to advanced cognitive understanding and metacognitive awareness and control."

\section{Some Modes of Reflection}

Richards and Lockhart (1994:1) define the reflective approach to teaching as one in which teachers :collect data about teaching, examine their attitudes, beliefs, assumptions, and teaching practices, and use the information obtained as a basis for critical reflection about teaching.: The same authors remind us that traditionally, supervisors may provide feedback to teachers at the end of their classroom visits, and this remains an important source for improvement and development. However, by using one or more of the reflection modes and techniques educators can examine their own performance individually, or collaborate with a colleague. The authors argue that instead of waiting for an external source as an impetus for change, educators can take the initiative and gather their own information about their own practice. By doing this, they can take decisions, achieve more independence, and initiate change.

By the same token, Oberg and Artz (1992:139) believe the action of reflection is not just an exercise to produce some descriptive material, it is rather, critical reflection which :requires intensive reflection on self as teacher", for example, :I must ask myself who I am, what I do, how I do it". The direct aim of this reflective thinking, the authors claim is "My hope is always that I may understand myself and my teaching more clearly."

Reflective thinking is often equated with critical thinking, while others see it as a form of logical thinking. It should be mentioned that critical thinking has a very important place in courses in disciplines such as Business. The 'ProblemSolving Method', or the 'Case-Study Method' has come to be an essential requirement for any business student. The Problem-Solving Method is discussed by Dewey (1933), who is considered by many as one of the inventors of reflective thinking. He states that "Reflective thinking generally addresses practical problems, allowing for doubts and perplexity before possible solutions are reached" (p34). Dewey defines the process of reflection in this mode as "an intellectualization of the difficulty or perplexity that has been felt (directly experienced) into a problem to be solved, a question for which the answer must be sought" (p:107). Copeland et al (1993) confirm this important function of reflection saying that "engaging in reflective practice involves a process of solving problems and restructuring meaning" (pp:348358). This process is similar to the one used in Business, for example. Copeland et al illustrate the steps as:

\section{A problem is identified.}

2. Having highlighted the problems, solutions begin to shape in the teacher's mind and one or more are generated. But :the reflective teacher is the one who is aware of the underlying sources which guide the solutions being considered" (p. 353).

3. The best solution is selected and implemented. Copeland et al affirm that the reflective educator is involved in action and in ensuring the implementation of solutions: :reflection involves action as well as deliberation" (p. 358).

4. Finally, the immediate outcomes of a solution are measured in the light of student:s improvement and the question asked is: Has students' learning improved as a result of implementing this solution?

\section{When, How, Where, Why and How Often Reflection Happens}

Teacher educators and professionals answer these questions saying that reflection is a mental activity that can happen before action, during action and/or after action (Schon 1983). For example, a teacher can reflect while planning his/her lesson. The objective of this reflection could be to speculate on the outcomes of this plan or on how students will react to it; alternatively this reflection could have been triggered by a felt difficulty in previous lesson(s), and as a result, considerations and changes are incorporated in the new plan. Also, a teacher might reflect at the end of a lesson thinking about what went right, what students learnt, and what went wrong. Reflection can take place anywhere, for example in the car while going home or going to work. In summary, there are three main states of reflection: reflection-before-action, reflection-in-action, and reflection-on-action.

Schon (1983) emerged as a leading figure in the literature of reflection with his new interpretation and new conceptualization of reflection. His distinction between :knowing-in-action:, :reflection-in-action: and :reflection-on-action: 
came into being with the advent of his book 'The Reflective Practitioner' in 1983, and these terms have been used by practitioners since then. According to Schon, knowing-in-action is :tacit knowledge:: spontaneous awareness which enables us to execute tasks fairly automatically. Schon notes that "our spontaneous knowing-in-action usually gets us through the day. On occasions, however, it doesn't" (p:23). An error, or a surprise as he calls it, may occur and cause us to stop and think in the midst of an action and reflect on it. This reflection helps us reshape the action and put things right. In this case, we reflect-in-action: in other words, reflection-in-action is an intuitive, immediate response to an error (surprise) during knowing-in-action (work), and the reflective practitioner responds as a researcher in action, whose aim is to change the world. "Reflection-in-action has a critical function, questioning the assumptional structure of knowing-inaction" (ibid:28). Altrichter et al (1993:205) cite Schon's analogy of reflection-in-action: "Reflection-in-action resembles, as Schon says, a reflective conversation with the situation."

By contrast, reflection-on-action takes place after the event. The teacher has the time to reflect on the events and evaluate the outcomes of his/her actions in the classrooms, and on his/her students' learning. This kind of reflection is different from reflection-in-action, as it is not an intervention, but a retrospective process which can extend to days or weeks. In the words of Russell and Munby (1992:3), "Reflection-on-action refers to the systematic deliberate thinking back over one's actions that characterizes much of what we do when we pause after an action and attend to what we believe has occurred.: Altrichter et al (1993:206) have given reflection-on-action more scope and more importance as they claim that, "to cope with difficult and complex problems, take control of our practice so we can change if we so wish, and fulfil our responsibilities to society, we have to involve reflection-on-action".

Roberts (1998) argues against Schon's reflection-in-action theory, which is based on the simultaneity of reflection and action, saying that reflection needs some time away from the classroom, and cannot be done while a class full of students learners are :gazing at you:. Nevertheless, Mitchel and Percmarland (1989) in their research on teacher thinking have discovered instances where educators appear to engage in reflection-in-action unconsciously when decisions have to be taken immediately and urgently. They cite a situation that was revealed by their research: "When the teacher's plans or homework tasks were challenged by students, she took their reactions into account by sometimes making mid-lesson changes" (p118). This type of thinking complies with Schon's intervention theory, as some researchers have called it. That same teacher responded immediately to that surprise and made the necessary changes which, as she claimed, kept her students interested, adjusted the lesson plan and gave it more meaning, and impressed her students that she valued their opinion. This kind of reaction by the teacher in the above example complies with one of Griffiths and Tann's (1992) reflection formulas: React-Monitor-React-Rework-Plan-Act (Repair). This is a good example of how reflection-in-action can be very useful for educators as it helps them to act appropriately in certain critical moments through their classroom interaction with their students.

Another interesting instance of teacher thinking, a kind of reflection-in-action unearthed by the same researchers, was described as 'mood-assessment'. In this mode of reflection-in-action, the teacher will take decisions on lesson activities and procedure based on students' facial expressions or on the way they answer her 'good morning', as these factors can indicate to a reflective practitioner the mood of their students and their readiness for the type of learning on that day. In other words, educators assess their learners' mood and reflect, then react by coming up with a suitable plan for that day. This, it can be said, involves reflective thinking and reflective action as well.

Another important contribution to the notion of reflection is Van Mannen's (1977) 'levels of reflectivity'. Van Mannen claims that reflecting and theorizing occur at three levels: technical, practical, and critical/emancipatory. The technical level is concerned with reflecting on success in attaining goals, for example, or in maintaining class order, or in helping students to understand a concept. Practical reflection is concerned with how actions, values and assumptions are linked: for example, teachers select an aspect of their teaching and reflect on it. By contrast, critical (emancipatory) reflection enables teachers and student teachers to see how their efforts are shaped by societal and institutional structures. They can also discover how the ideologies used in their teaching are in conflict with their pupils' interests. The outcome of this reflection will encourage them to contest the processes and ideologies of the educational system (McIntyre 1993).

One more model of reflection is presented by Griffiths and Tann $(1992: 78,79)$. In this model five levels of reflection are suggested:

1. Act-react (Rapid reaction). At this level:the teaching action is immediate and routine:automatic reaction.

2. React : monitor - react/rework : plan - act (repair). At this level, although there is pause for thought, it is 'on the spot', and very quick.

3. Act - observe - analyse and evaluate - plan - act (Review). At this level, thought and reflection are going on after the actions are completed. For example a teacher may reassess how a student is to be managed.

4. Act - observe systematically - analyse rigorously - evaluate - plan - act (research). At this level, observation becomes systematic and sharply focused. The process of collecting information, analysing it and evaluating it may be a matter of weeks or months.

5. Act - observe systematically - analyse rigorously - evaluate - theorise - plan - act (Retheorising and reformulating). This is the level of abstract, rigorous reflection, which is formulated and reformulated, over a matter of months and years. In the process the educators' own theories will become changed. This level cannot occur unless the educator is reading theory critically. 
Another mode of reflection, or appropriate conditions for reflection to occur, is what has been called in the literature collaborative reflection (Baird, 1992; Richert, 1992). These authors claim that reflecting in a group or with a partner reveals more than personal activity; in fact, this activity puts other aspects of teaching under scrutiny. For example, in peer observation, data gathered by the observer will help the observed reflect on the social aspect of classroom atmosphere. As an example, the data may highlight a defect in the interaction between teacher and students and among students themselves, or it may uncover the passivity of certain students. A teacher may want to emphasize the clarity of the concept he/she is teaching, which can lead to more lecturing, for example. If another educator is observing that particular part of the lesson, s/he may notice that the teacher is not involving her students and the emphasis is, perhaps unconsciously, put on :teaching: rather than :learning:. A reflective discussion between the two offers the opportunity to focus on that issue.

Reflection will happen and be more effective if it is based on data gathered by educators. So, how can educators capture that moment of their practice and reflect on it? Of course, there are techniques and strategies which support this process.

\title{
Techniques and Strategies that Teachers Can Use to Reflect on Their Practice
}

There are several approaches and procedures involved in classroom investigation that can stimulate reflection. Richards and Lockhart (1994) provide a thorough and well-detailed description of these approaches accompanied by examples, questionnaires, and case studies, and remind us that

\begin{abstract}
"in every lesson and every classroom, events occur which the teacher can use to develop a deeper understanding of teaching. Teachers sometimes fail to exploit these events, letting the momentum of all the events of the day take precedence. And yet these experiences can serve as the basis for critical reflection, if teachers can find ways to capture the thoughts of and reaction to the events, as well as ways to gather information about the events themselves. From this basis, teachers can develop strategies for invention or change, depending on their needs (p. 6)."
\end{abstract}

Richards and Lockhart have made a very valid point about capturing opportunities for reflection, and not letting other considerations control the day. So, how can teachers exploit those moments for reflection, and what techniques can enable them to reflect effectively? The authors present six strategies for this purpose (p. 6):

1. Teaching journal: written accounts of teaching strategies.

2. Lesson reports: written accounts of lessons which describe the main features of the lesson.

3. Surveys and questionnaires: activities such as administering or completing a survey designed to collect information on a particular aspect of teaching or learning.

4. Audio and video recordings: recordings of a lesson or part of a lesson.

5. Observation: tasks completed by a peer observing a teacher's class.

6. Action research.

Richards and Lockhart also add to this list another important approach worthy of consideration: asking yourself questions. They affirm that critical reflection involves asking questions. These questions put by the practitioner are supposed to trigger thinking about a certain aspect of his/her performance. They can be about beliefs, teaching style, the kind of educator I am, whether beliefs influence my teaching, my learners: opinion about my role, my lesson structure, what kind of interaction is taking place in my classroom, etc. (A complete list of these questions is provided in @Appendix 1).

Another procedure 'in how practitioners can begin their engagement with a reflective cycle', is presented by Griffiths and Tann (1992) who suggest first pausing to reflect as to what is happening in a given situation and identifying the issue in plain words, and then using a video to record what is happening in the classroom. Griffiths and Tann, as well as Richards and Lockhart (1994) comment that by watching a video of a teaching event in a classroom, practitioners can gain a more objective perspective and notice any contradictions or mismatch between what they are doing and what they intend to do. The video recording, in this case, gives practitioners the stimulus to reflect, ask 'why', and then probe how this situation can be adjusted or corrected. Thus, personal theories and beliefs are made explicit for examination.

\section{Is a Reflective Practitioner Better Than an Unreflective Practitioner?}

The answer to this question might not necessarily be 'yes'; however, the rich literature on reflection spells out the significant role that reflectivity plays in the professional development of educators. Those who reflect continuously are developing their practice and may reach higher standards of performance. Griffiths and Tann (1992: 73) comment that :reflection on one's own practice (theories) is precisely what distinguishes the reflective practitioner model". Baird (1992) adds that a reflective practitioner is one who wants to be a better teacher because he/she is committed to improving their practice. A reflective practitioner might be superior because s/he believes teaching is more than enhancing metacognitive skills such as control, awareness and knowledge. He explains, :better teaching :is not just learning better teaching techniques. It is undergoing fundamental change in one's attitude, perceptions, conceptions, beliefs, abilities and behaviours" (ibid: 33 ). 
A reflective educator is constantly evaluating the outcomes of his/her practice and is developing continuously as a result. This process seems likely to lead to a more effective teaching situation. In addition, reflective practitioners are critical thinkers who persist in solving their problems. Non-reflective educators, by contrast, may stagnate and never develop professionally; however, this is an area which would benefit from some empirical investigation. Williams (1999: 9) reminds us, :Teachers need to become aware of their own theories and engage in a process of constantly monitoring them; that is, to ask, :what does my practice tell me about what I think and what my beliefs are?: Reflection then is directed towards specific pedagogical problems and issues.:

\section{What Are the Potential Benefits of Reflection for Educators?}

The following summarises some of the thoughts from the literature on how reflection may contribute to the professional development of educators:

1. "Personal reflection:helps teacher candidates develop a professional sense of self and use the knowledge to create humane classroom environment". (Valli, 1993:15).

2. :reflection focus[es] on more than just the instrumental means of instructional delivery", or technical rationality. According to Russell and Munby (1992:3), reflection means more than that, they confirm, :the goal of the enterprise is to develop a cadre of teachers who are thoughtful about their work."

3. "The focus here is on reflection for self-enlightenment: confronting the self to examine feelings and emotions about teaching students and school setting"(Valli:15).

4. "The results of reflection vary:a new comprehension can be an improved ability to carry out an act of reflectivity; it may be an additional changed belief about a particular topic in such areas as curriculum, or instruction - pedagogical content knowledge; it can be an attitude or value about what is important to teach, etc." (LaBosky, 1993:35).

5. "Certainly it is through reflection on their own teaching that novices can be helped to see the need for ideas from other resources. And through reflection they begin to gain access to new ideas that can be useful to them: and:will increasingly be able to learn" (McIntyre, 1993:44).

6. Mclntyre adds that reflection assists novices to reflect on their problems and needs, second, it will guide their practice in the long run when they become more experienced educators.

7. One of the important aims of reflection is that :teachers should become active agents in the production of a new pedagogy discourse, rather than merely the consumers of professional knowledge produced by academics and educational researchers" (Edwards and Bruton,1993:156). Oberg and Artz (1992:135) look at it from another perspective as they say, "We find the knowledge we evolve from our own experience settles much deeper and lasts much longer than the knowledge we borrow from others.: This confirms that the self is a very significant source for practitioners.

8. "The process of learning the skills needed to be a reflective practitioner will include the skills required for academic success" (ibid:114).

9. Reflection is more accurate than intuition, as the latter can be deceptive. (Gilpin 1999)

10. The aim of learning reflection is :for teachers to develop a personal theory of teaching and through reflective practice to learn from their experience throughout their career" (Pennington, 1999:107)

11. From a constructivist point of view, Roberts (1998) thinks that reflective thinking can provide the ground for student teachers to reconstruct their personal theories.

12. Roberts adds as another advantage of reflectivity that it promotes collegiality and reduces privatist practices.

13. Reflection is seen by Russell and Munby (1992:3) :as a central approach to the acquisition of professional knowledge.:

These merits of reflection are supported from personal experience by Hiang (1998, pp 14-16), an English language educator from Sarawak, Malaysia, who participated in a self-reflection course that was conducted at the University of Leeds, which formed part of a B.A. TESOL. Hiang states that by being involved in diary writing as a means of reflection, and discussing the contents with other student teachers and tutor, he learnt the following things:

- to be more innovative, observant and resourceful.

- to be more receptive to new ideas and methods.

- to move away from rigid, exam-oriented classrooms.

- that the purpose and the intention of a lesson are very important.

- that time is a very important factor for learning to take place.

- to be more tolerant and more receptive to others' opinions and ideas. 
Hiang concludes his article by saying that :diary-writing is a powerful way of effecting self-reflection in the process, changing attitudes" (p.16).

However, although educators can see the advantages of learning how to reflect on one's own teaching practice, they have also come across a number of obstacles that can hinder the learning of reflection by novices and by more experienced teachers.

\section{Barriers to Reflection by Educators}

There are a number of potential barriers to becoming reflective that are mentioned in the literature, and these are related to psychological, emotional, and constitutional constraints. They are also related to attitudes of teachers and their work environments. So, what are these barriers?

Firstly, the role of tutors or supervisors as assessors in professional development programs may act as a barrier to promoting reflection among educators when the latter hesitate to reveal their real concerns and difficulties (Calderhead,1993). This can be overcome if trainees are convinced that the observer:s report is a constructive future plan rather than a criticism of their practices. Besides, the observer must try to create an atmosphere of trust and ensure that the trainees feel secure and deal with any feelings of fear and anxiety they may have.

Secondly, the emotional element in reflection is often rejected and rationality stressed in teacher education and professional development programs, and Western cultures tend to stress the analytical method that is based on objectivity, and emphasize emotional detachment. This is seen by critics of such programs as an obstacle to learning reflectivity by novices (Calderhead,1993). From this perspective, Richert (1992:187) suggests that, "Learning to teach is an emotional experience:if beginning teachers have an opportunity to respond to the emotional content of their work by articulating and showing it to others, they are more likely to move to other areas or levels of analysis as they contemplate their experiences in the classroom.: Teachers: feelings about teaching and learning must be considered particularly in the early stages of a person:s career. So, they need to be given the opportunity to express them, and project them so they can contemplate and think of their validity. Complete exclusion of emotions, in certain cultures, can cause a decline in morale.

Novices: attitudes and aptitudes can also be a determining factor in the speed and effectiveness in acquiring reflectivity. LaBosky (1994) has grouped novices into two categories based on her research into novice teachers' thinking ability; the Common Thinkers and the Alert Thinkers. She discovered that the Alert Thinkers are quick, reflective, motivated and look for opportunities. By contrast, she found the Common Thinkers to be slower, less reflective and showing less ability and motivation to think. "Thus both ability and attitude appear to be necessary for reflective thinking" (ibid:30). Unfortunately, the Alert thinkers: attitude and abilities are not inherent in many novices and that makes learning reflection difficult for them, and very demanding for their tutors. They must be grouped with Alert thinkers and their tutors may have to deal with them on an individual basis. This philosophy seems to ignore that people have different cognitive processes and their making sense of the world around them is based on certain personal factors that are different from one person to another. Consequently, trainees should not be polarized into superior and inferior thinkers. The more appropriate method is to listen to individuals and help them construct their knowledge and grow professionally by providing them with the opportunity and the environment to be Alert Thinkers.

Educators, particularly when entering the profession or entering unfamiliar teaching situations, may equate reflection with unnecessary theoretical knowledge, as they feel their first and immediate need is to learn technical skills that help them to survive in their jobs (Mclntyre, 1993). This barrier can be overcome if educators are shown real life examples and cases in which reflection has led to a more effective teaching practice. Additionally, they need to be encouraged to experiment reflectivity in the field and discover by themselves.

McIntyre (1993) claims that novices depend more on intuition as they have no experience to explore or draw on. In this sense, reflection is more suited to experienced teachers. On the other hand, this generalization seems to ignore the fact that everyone has some sort of experience. For example, those novices have observed tens of teachers in their own experience of education, and must have seen many different teaching techniques. So it is unfair to say that they have no experience.

Local educational culture may not encourage reflection. This culture may tend to persuade educators that advanced and improved knowledge is gained from external resources rather than from personal experiences (Russel,1994). In addition to that, the prescriptive nature of institutional curricula may force educators to work in isolation, deterring collaborative reflection. Baird (1992) criticises this privatist behaviour in teaching by commenting that although teachers work alongside each other, they follow an isolationist nature of teaching which considers the classroom of another as sacrosanct. Pisove (1999) comments that this sacred privacy of the classroom compounds novices' problems and doubles their anxiety particularly in the demanding early months of their career in an unfamiliar setting. If supervisors build up teams of teachers who co-operate and act as :critical friends: through trust and constructive feedback, the sacrosanct syndrome will disappear gradually and an atmosphere of collaboration will prevail in the institution.

Although reflection is included in almost all teacher education and professional development programs, the problem is that the context is the lecture room and not the real world, and the tools are videos, tapes, print, etc. (Gilpin,1999). Such programmes need to go beyond those means of trying to teach reflectivity, and observe educators in the classrooms. If theory is put into practice and educators can see that it works for them, they might be more motivated to try reflective approaches. 
Learning reflection requires involvement in learning certain demanding sub-skills which may not be easy for many people. Gilpin explains that :reflection consists of a number of elements: noticing, reasoning, and analysis, change, questioning and affective involvement: ( $p: 115)$. If professional development programmes want teachers to learn reflectivity, they have to provide them with the as many techniques as available and help them practice these through interaction with each other.

Another barrier to developing reflection is when educators begin to see it as another 'mantra', in which case they may resist it (Gilpin 1999). It will be a barrier to many teachers if reflection is imposed on them as another policy. Many will see it as another added burden and may not take it seriously. Instead, reflectivity must be introduced as another useful strategy to self-evaluation and self-criticism. If educators are provided with the skill and knowledge to conduct reflection, their work load will be less as they become more effective time managers and problem solvers.

Inexperienced educators in particular may draw on the rationale presented to them in professional development programmes to answer 'why' questions. In this case, "it is contradictory, then, to try and apply an innovative framework of reflection to a reinforcement model of training and learning" (Selby, 1999:136): if teachers are trained to follow a certain line and are not supposed to deviate, then they will not feel secure in the face of unpredicted events or unfamiliar situations. Educators must be given a certain amount of autonomy and professional development programmes have to be flexible and give them a choice. Too much rigidity might kill creativity.

Certain educators may perceive reflection as not generally associated with working as a teacher, perceiving it instead as a more academic pursuit (Elbaz,1988; Mcnamara,1990). This view or assumption can be erased if educators are given evidence of the applicability of reflection in their daily practice. This depends largely on how professional development programmes are tailored.

Another potential barrier is that teachers may feel that they are not familiar with the genre of reflective writing, and this may inhibit their willingness to reflect (Hatton and Smith, 1995). They need to be given the necessary training to reflect, whether in writing or through discussion, so their self-esteem and self-confidence are increased.

Finally, there is some confusion and uncertainty among many educators in how they perceive reflection. Some may perceive it as a skill, others as an attitude, or as an approach to doing something (Oberg and Artz, 1992). There is no evidence that people are born reflective or critical thinkers: reflection is a skill and an attitude. Very often confusion results from the ambiguity of the situation, but if educators are equipped with the skill to reflect, they may change their attitude and may make the best use of it.

Indeed there are many barriers to reflection as has been explained in the literature. However, this literature may not have presented all the barriers as certain cultures have different barriers. For example, in certain cultures, people:s bringing-up and their conditioning prevent them from reflection and they fear change. So, there is a need for teachers: educators to take into consideration all those barriers and come up with solutions.

There is also a need for research to see if educators: teaching performance is affected by reflection. Researchers could gain more information, for example by looking at the learners: achievements and attitudes in a class where the teacher has been reflecting on his/her practice. The following section will present a plan for such research into teachers: practice.

\section{A Research Agenda}

Copeland et al (1990) urge researchers :to verify the assumed positive relationship between reflectivity and teacher effectiveness" (p:355). For that reason, they present us with a research agenda that contains a number of questions which can lead our research into educators: utilization of reflectivity and its effects on their performance. Key research questions include the following:

1. Who is a reflective educator?

2. Is there a relationship between students' achievements and the ability of their teacher to reflect?

3. Are the students of unreflective teachers less successful?

4. Do teachers have the tendency to reflect or do they vary in this matter?

5. Is reflectivity a stable condition or is it developmental and situational?

6. Is there a relationship between reflectivity and other attributes of teachers?

7. Do the career trajectories of highly effective teachers appear to be different from their less reflective colleagues?

Seeking answers to these questions will demand a great deal of effort on the part of researchers. In addition, educators who will be the subjects for this research have to reveal a lot of information about their performance (something not all teachers are willing to do) for researchers. Moreover, the research will have to involve students of those teachers to answer questions 2 and 3. In spite of all this, Copeland's et al research agenda can be an excellent ground for generating interest in reflection and promoting it as a valid tool for enhanced performance and professional development among educators. 


\section{Reflection In Teaching in the UAE : A Preliminary Study}

In my small scale research into reflectivity among colleagues in the UAE, I will attempt to answer some questions. The other question that has arisen in the literature about the nature of reflection, which this paper will attempt to answer, is: Is reflection an attitude or a set of skills, or both? [@Did you answer this or explore it?]

[Editor: Link to research report under construction : online soon].

\section{Discussion/Reflection Questions}

1. How often are you able to stop and reflect on your activities and decisions as an educator?

2. What support does your institution currently offer for individual or collaborative reflection by educators?

3. What suggestions could you make for further support?

\section{References}

Altrichter, et al (1993). Teachers Investigate Their Work. London: Routledge.

Atkins, S. and. Murphy, K. (1993). Reflection, a Review of the Literature. Journal of Advanced Nursing 18: 1188-92.

Baird, J.R. (1992). Collaborative Reflection, Systematic Enquiry, Better Teaching. In Russell, T. and Munby, H. (eds). Teacher and Teaching: From Classroom to Reflection. Bristol: The Falmer Press.

Barlets, N. (1999). How Teachers Use Their Knowledge of English In Trappes-Lomax, H. and McGrath, I. (Eds). Theory in Language Teacher Education. Harlow: Longman. 46 : 56.

Bengtsson, J. (1995). What is Reflection? On Reflection in the Teaching Profession and Teacher Education. Teachers and Teaching: theory and practice, $1 / 1$.

Byram, M. (1999). Source Disciplines for Language Teacher Education. In Trappes-Lomax, H. and McGrath, I. (eds). Theory in Language Teacher Education. Harlow: Longman. $71: 81$.

Calderhead, J. and Gates, P. (eds). (1993). Conceptualising Reflection in Teacher Development. London: Falmer Press.

Copeland, W. et al. (1993). The Reflective Practitioner in Teaching: Toward a Research Agenda. Teaching and Teacher Education. 9/4, pp $347: 359$.

Covey, R.S. (1989). The 7 Habits of Highly Effective People : Powerful Lessons in Personal Change. New York: Fireside.

Cross, K. (1988). In Search of Zippers. (Bulletin of American Association for Higher Education 40, pp 3-7). In Richards, JC. and Lockhart, C. 1994. Reflective Teaching in the Second language Classroom. New York: Cambridge University Press.

Dewey, J. (1933). How We Think. Boston: D.C. Heath and Company.

Edwards, A. and Bruton, D. (1993). Supporting Reflection in Teacher Learning. In Calderhead, J. and Gates,P. (eds). Conceptualising Reflection in Teacher Development. London: Falmer Press

Elbaz, F. (1988). Critical Reflection on Teaching: Insights from Freire Journal of Education for teaching. 14(2), 171-181.

Eraut, M. (1994b). The Acquisition and Use of Educational Theory by Beginning Teachers. In Harvard, G. and Hodkinson, P. (eds). 69-88.

Gilpin, A. (1999).. A Framework for Teaching Reflection. In Trappes-Lomax, H. and McGrath, I. (eds). (1999). Theory in Language Teacher Education. Harlow: Longman. Pp 109: 118.

Griffiths, M. and Tann, S. (1992). Using Reflective Practice to Link Personal and Public Theories. Journal of Education for Teaching. 18/1, pp $64: 84$.

Hatton, N. and Smith, D. (1995). Reflection in Teacher Education: Towards Definition and Implementation. Teaching and Teacher Education. 11/1, pp 33-49.

Hiang, N.J. (1998). Diary-Writing for Self-Reflection. The Teacher Trainer, 12/2.

Kumaravadivelu, B. (1999). Theorising Practice, Practising Theory: the Role of Critical Classroom Observation. In Trappes-Lomax, H. and McGrath, I. (eds). (1999). Theory in Language Teacher Education. Harlow: Longman . 33 : 45.

LaBoskey, V.K. (1993). A Conceptual Framework for Reflection in Pre-service Teacher Education. In Calderhead, J. and Gates,P. (eds). (1993). Conceptualising Reflection in Teacher Development. London: Falmer Press. 
Lucas, P. (1991). Reflection, New Practices and the Need for Flexibility in Supervising Student Teachers. Journal of Further and Higher Education, 15/2, pp 84-93.

McGrath, J. (1997). (ed). Learning to Train: Perspectives in the Development of Language Teacher Trainer. London: Prentice Hall.

McGrath, I. (1999). Cultural Encounters of the Theoretical Kind. In Trappes-Lomax, H. and McGrath, I. (Eds). (1999). Theory in Language Teacher Education. Harlow: Longman. 82- 96.

McIntyre, D. (1993). Theory, Theorizing and Reflection in Initial Teacher Education. In Calderhead, J. and Gates, P. (eds). (1993). Conceptualising Reflection in Teacher Development. London: Falmer Press.

McNamara, D. (1990). Research on Teachers' Thinking: Its Contribution to Educating Student Teachers Think Critically. Journal of Education for Teaching, 16(2)., 147-160.

Mitchel, J. and Percmarland. (1989).. Research on Teacher Thinking: The Next Phase. Teaching and Teacher Education. 5/2, pp 115-128.

Moon, A, J. (1999). Reflection in Learning \& Professional Development: Theory and Practice. London: Kogan Page Limited

Oberg, A. and Artz, S. (1992). Teaching for Reflection: Being Reflective in Russell, T. and Munby, H. (eds). (1992). Teacher and Teaching: From Classroom to Reflection. Bristol: The Falmer Press.

Pennington, M.C. (1999). Rules to Break and Rules to Play By: Implications of Different Conceptions of Teaching for Language Teacher Development. In Trappes-Lomax, H. and McGrath, I. Theory in Language Teacher Education. Harlow: Longman. 99-108.

Pisove, M. (1999). Novice Teacher in the Staff-Room. The Teacher Trainer 13/3.

Reis Jorge, J.M. (1997). The Trainer as Enquiring Practitioner: Setting an Example by Doing Research with Teaching. In McGrath, J. (ed). (1997). Learning to Train: Perspectives in the Development of Language Teacher Trainer. London: Prentice Hall.

Richards, J.C. (1989). Beyond Training. New York: CUP

Richards, JC. and Lockhart, C. (1994). Reflective Teaching in Second Language Classroom. New York: Cambridge University Press.

Richards, K. (1999). Theory and Practice: Design an Argument in Day-to-day Teaching. In Trappes-Lomax, H. and McGrath, I. (eds). (1999). Theory in Language Teacher Education. Essex: Longman.

Richert, A.E. (1992). The Content of Student Teachers Reflection within Different Structures for Facilitating the Reflective Process. In Russell, T. and Munby, H. (eds). (1992). Teacher and Teaching: From Classroom to Reflection. Bristol: The Falmer Press.

Roberts, J. (1998). Language Teacher Education. London: Arnold.

Russel, T. (1993). Critical Attributes of a Reflective Teacher: Is Agreement Possible?. In Calderhead, J. and Gates,P. (Eds). 1993. Conceptualising Reflection in Teacher Development. London: Falmer Press.

Russell, T. and Munby, H. (eds). (1992). Teacher and Teaching: From Classroom to Reflection. Bristol: The Falmer Press.

Schon, D.A. (1983). The Reflective Practitioner. London: Temple Smith.

Schon, DA. (1987). Educating the Reflective Practitioner. San Francisco: Jossey-Bass Inc., Publishers.

Selby, G. (1999). Assessing Reflection in the Pre-Service. The British Council Practicum. Tokyo. In Trappes-Lomax, H. and McGrath, I. (eds). (1999). Theory in Language Teacher Education. Harlow: Longman. 133-145.

Trappes-Lomax, H.. and McGrath, I. (eds). (1999). Theory in Language Teacher Education. Essex: Longman.

Valli, L.R. (1993). Reflective Teacher Education Programs: An Analysis of Case Studies. In Calderhead, J. and Gates,P. (eds). Conceptualising Reflection in Teacher Development. London: Falmer Press.

Van Mannen, M (1977). Linking ways of knowing with ways of being practical. Curriculum Inquiry 6/3, 205-28.

Von Wright, J. (1992). Reflection on Reflection. Learning and Instruction 2, 59-68.

Williams, M. (1999). Learning Teaching: A Social Constructivist Approach. Theory and Practice, Theory with Practice? In Trappes-Lomax, H. and McGrath, I. (eds). (1999). Theory in Language Teacher Education. Harlow: Longman. 11-20. 


\section{Appendix}

\section{Critical reflection involves asking questions such as the following:}

- How can I collect information about my teaching?

- What are my beliefs about teaching and learning, and how do these beliefs influence my teaching?

- Where do these beliefs come from?

- What kind of teacher am I?

- What beliefs do my learners hold about learning and teaching?

- How do these beliefs influence their approach to learning?

- What learning styles and strategies do my learners favour?

- What kind of planning decisions do I make use of?

- What kind of on-the-spot decisions do I make use of?

- What criteria do I use to evaluate my teaching?

- What is my role as a teacher?

- How does this role contribute to my teaching?

- How do my learners perceive my role as a teacher?

- What form or structure do my lessons have?

- How do I communicate goals to my learners?

- How effectively do I utilise learning opportunities within a lesson?

- What kind of interaction occurs in my classroom?

- What interactional styles do my learners fovour?

- What kind of learning activities do I employ?

- What is the purpose of these activities?

- What patterns of language use occur when I teach?

- How do I modify language to facilitate teaching and learning?

- What opportunities do learners have for authentic language use in my lessons?

(Richards and Lockhart, 1994:2) 